\title{
Clinical and bacteriological features and prognosis of ascitic fluid infection in Chinese patients with cirrhosis
}

Nian-zhi Ning ${ }^{1 \dagger}$, Tao $\mathrm{Li}^{1+}$, Ju-ling Zhang ${ }^{2+}$, Fen Qu${ }^{2}$, Jie Huang ${ }^{1}$, Xiong Liu', Zhan Li ${ }^{1}$, Wei Geng ${ }^{2}$, Jun-liang Fu ${ }^{3}$, Wang Huan ${ }^{2}$, Shu-yong Zhang ${ }^{2}$, Chun-mei Bao ${ }^{2^{*}}$ and Hui Wang ${ }^{1 *}$

\begin{abstract}
Background: Spontaneous bacterial peritonitis (SBP) and bacterascites (BA) represent frequent and serious complications in cirrhosis patients with ascites. However, few detailed data are available regarding the clinical and bacteriological feature of SBP or BA patients in China.

Methods: We retrospectively analyzed bacteriological and clinical characteristics of patients with SBP and BA at Beijing 302 Hospital in China from January 2012 to December 2015.

Results: A total of 600 patients with SBP $(n=408)$ or BA $(n=192)$ were enrolled. Patients with BA appeared to have a less severe clinical manifestation and lower mortality rate than patients with SBP. Gram-negative bacteria formed the majority of pathogens in SBP (73.9\%) and BA (55.8\%) cases. Higher ascitic fluid polymorphonuclear leucocytes (PMN) count and hepatocellular carcinoma were independent risk factors for BA episode progressing to SBP. The concentration of blood urea nitrogen (BUN) was independent risk factor for 30-day mortality of BA patients. For patients with SBP, the independent risk factors for 30-day mortality were age, Model for End-Stage Liver Disease (MELD) score, septic shock and hepatocellular carcinoma. Patients with third-generation cephalosporin or carbapenems resistant infection had a significantly lower survival probability. There were significant differences in clinical characteristics and outcome among the major bacteria. Multivariate analysis showed that patients infected with Klebsiella spp. had higher hazard ratio of 30-day mortality.

Conclusion: Our study reported the bacteriological and clinical characteristics of patients with SBP and BA. Higher ascitic fluid PMN count and hepatocellular carcinoma were found to be independent risk factors for BA episode progressed to SBP. Outcome of ascitic fluid infection in patients with cirrhosis was influenced by the type of bacteria and antimicrobial susceptibility.
\end{abstract}

Keywords: Cirrhosis, Spontaneous bacterial peritonitis, Bacterascites, Causative pathogens, Mortality, Risk factor

\footnotetext{
*Correspondence: bcm2003@sina.com; geno0109@vip.sina.com

${ }^{\dagger}$ Nian-zhi Ning, Tao Li and Ju-ling Zhang contributed equally to this work.

${ }^{2}$ Clinical Diagnostic Center, Beijing 302 Hospital, No. 100 Western 4th Middle

Ring Road, Beijing 100039, China

${ }^{1}$ The State Key Laboratory of Pathogen and Biosecurity, Beijing

Institute of Microbiology and Epidemiology, No.20 Dongda Street,

Fengtai District, Beijing 100071, China

Full list of author information is available at the end of the article
}

(c) The Author(s). 2018 Open Access This article is distributed under the terms of the Creative Commons Attribution 4.0 International License (http://creativecommons.org/licenses/by/4.0/), which permits unrestricted use, distribution, and reproduction in any medium, provided you give appropriate credit to the original author(s) and the source, provide a link to the Creative Commons license, and indicate if changes were made. The Creative Commons Public Domain Dedication waiver (http://creativecommons.org/publicdomain/zero/1.0/) applies to the data made available in this article, unless otherwise stated. 


\section{Background}

Cirrhotic patients with ascites usually face poor outcomes, especially if infections such as spontaneous bacterial peritonitis (SBP) develop [1]. Prompt and appropriate empirical antibiotic therapy must be initiated immediately after the diagnosis of SBP to cover the most commonly isolated bacteria [2]. Previous studies showed that gram-negative bacteria, mainly Enterobacteriaceae, were major causative organisms of ascitic fluid infection [3, 4]. Third generation cephalosporins are the first line antibiotics to treat spontaneous bacterial peritonitis; however, it was showed that the initial treatment with cefotaxime, one of the most commonly used cephalosporins, failed more frequently than expected [5]. It may be explained by the change of causative pathogen profile and the emergence of antibiotic-resistant pathogens. In recent years, several studies have reported changes in the epidemiology of causative bacteria in SBP. Enterococcus spp. was increasingly recognized as an important pathogen of ascitic fluid infection for patients with cirrhosis. Reuken et al. confirmed a profound increase in the frequency of Enterococcal infection from 11\% to 35\% between 2000 and 2011 in a German tertiary center [6]. Piroth et al. found that Enteroccocci were isolated in $24 \%$ of ascitic fluid infection episodes, and in $48 \%$ from patients receiving quinolone prophylaxis in four French hospitals [7]. The emergence and spread of multi-drug resistant bacteria such as methicillin-resistant Staphylococcus aureus (MRSA), extended-spectrum beta-lactamases (ESBL)-producing Enterobacteriaceae and Carbapenemase producing (KPC) Klebsiella pneumonia are also of great concern since they may be associated with higher mortality rate [8]. In recent years, an increased prevalence of multi-drug resistant bacteria in SBP cases was reported $[9,10]$.

Liver diseases affect $\sim 300$ million people in China, and the incidence of liver cirrhosis has increased during recent years because of the low awareness of the perniciousness of liver diseases and low treatment rate for these patients [11]. Some studies have described the pathogens profile and drug resistance of SBP in cirrhotic patients in China $[12,13]$. However, those studies were limited by being single-center study and failed to investigate the characteristics and outcome of SBP. Thus, more timely and comprehensive studies on bacteriological and clinical characteristics of SBP and BA in China are necessary.

In this study, we aimed at assessing the possible changes in bacteria etiology of SBP and BA, the risk factors of 30-day mortality and the differences in clinical characteristics and prognosis among patients with different causative pathogens.

\section{Methods}

\section{Setting and study design}

This study was conducted at Beijing 302 Hospital, which is the largest liver disease hospital in China. The hospital's database holds records of clinical histories, disease manifestations, physical and laboratory findings, and treatments of admitted patients. Bacteriology laboratory files and patient characteristics were reviewed to identify all cases with positive ascitic fluid cultures in cirrhotic patients hospitalized in our institution from January 1, 2012 to December 31, 2015. Patients with secondary peritonitis were excluded from the study. Patients with a positive culture for common skin contaminants (coagulase-negative staphylococci, corynebacteria, propionibacteria, and Bacillus spp.) were also excluded.

\section{Definitions}

The diagnosis of cirrhosis was based on clinical, biochemical, histological and/or radiological findings. A diagnostic paracentesis was performed in all patients as recommended by European Association for the Study of the Liver (EASL) [2]. SBP was diagnosed when (a) ascitic fluid polymorphonuclear leucocytes (PMN) count $\geq 250$ cells $/ \mu \mathrm{L}$, (b) ascitic fluid culture was positive; (c) there was no evident intra-abdominal surgically treatable source for infection [2, 14]. The diagnosis of BA was made when (a) the ascitic fluid PMN count $<250$ cells $/ \mu \mathrm{L}$, (b) ascitic fluid culture was positive; (c) there was no evident intra-abdominal surgically treatable source for infection [2, 15]. Fever, chills, abdominal pain and abdominal tenderness were considered symptoms of peritonitis [15]. Severity of cirrhosis was assessed at the time of the SBP or BA diagnosis using the Model for End-Stage Liver Disease (MELD) score [16]. Nosocomial infection was defined as an infection that occurred $>48 \mathrm{~h}$ after admission to the hospital [17].

\section{Microbiological methods}

Ascitic fluid samples were extracted and inoculated into bottles at the patient's bedside by aseptic manipulation and cultured with BacT/Alert 240 automated blood culture system (BioMérieux France). White blood cell (WBC) and PMN were counted by Sysmex automatic cell analyzer XT-4000 (SYSMEX, Japan). Microorganism identification was performed using the VITEK-II auto microbe system (BioMérieux France). Isolated pathogens were tested for antimicrobial susceptibility using the disk-diffusion method and minimum inhibitory concentration testing. Antimicrobial susceptibility was judged according to guidelines of the Clinical and Laboratory Standards Institute (CLSI) [18]. 


\section{Empirical antibiotic therapy}

Third-generation cephalosporins (TGC), such as cefotaxime, were used as empirical therapy antibiotic in our hospital. Empirical antibiotic therapy initiated immediately on all patients with ascitic PMN count $\geq 250$ cells $/ \mu \mathrm{L}$, without the results of ascitic fluid culture. Bacterascites patients exhibit signs of systemic inflammation are also treated with cefotaxime. Otherwise, the bacterascites patient should undergo a second paracentesis when culture results come back positive. Patients in whom the repeat PMN count is $\geq 250 / \mu \mathrm{L}$ would be treated for SBP. Carbapenems were used in all severe patients with septic shock. Paracentesis was performed repeatedly $2-3$ days after initiation of antibiotic therapy to determine leukocyte and PMN counts in ascitic fluid.

\section{Statistical analysis}

Quantitative variables were given as the mean \pm standard deviation or the median (interquartile range). Student's $t$ test or Mann-Whitney U-test was used to compare continuous variables, and the $\mathrm{x}^{2}$ test or Fisher's exact test was used to compare categorical variables. Statistical differences among several groups were analyzed using one-way ANOVA or the nonparametric Kruskal-Wallis test, as appropriate. Risk factors for SBP development were determined by multivariate binary logistic regression including significant univariate predictors $(p<0.05)$ using stepwise backward elimination. The life-table method was used to compare survival probability for patients according to different variables. A Cox proportional hazard model analysis was carried out to identify independent predictors of 30-day mortality for every episode, defining death as the main event. Variables with $p<0$.

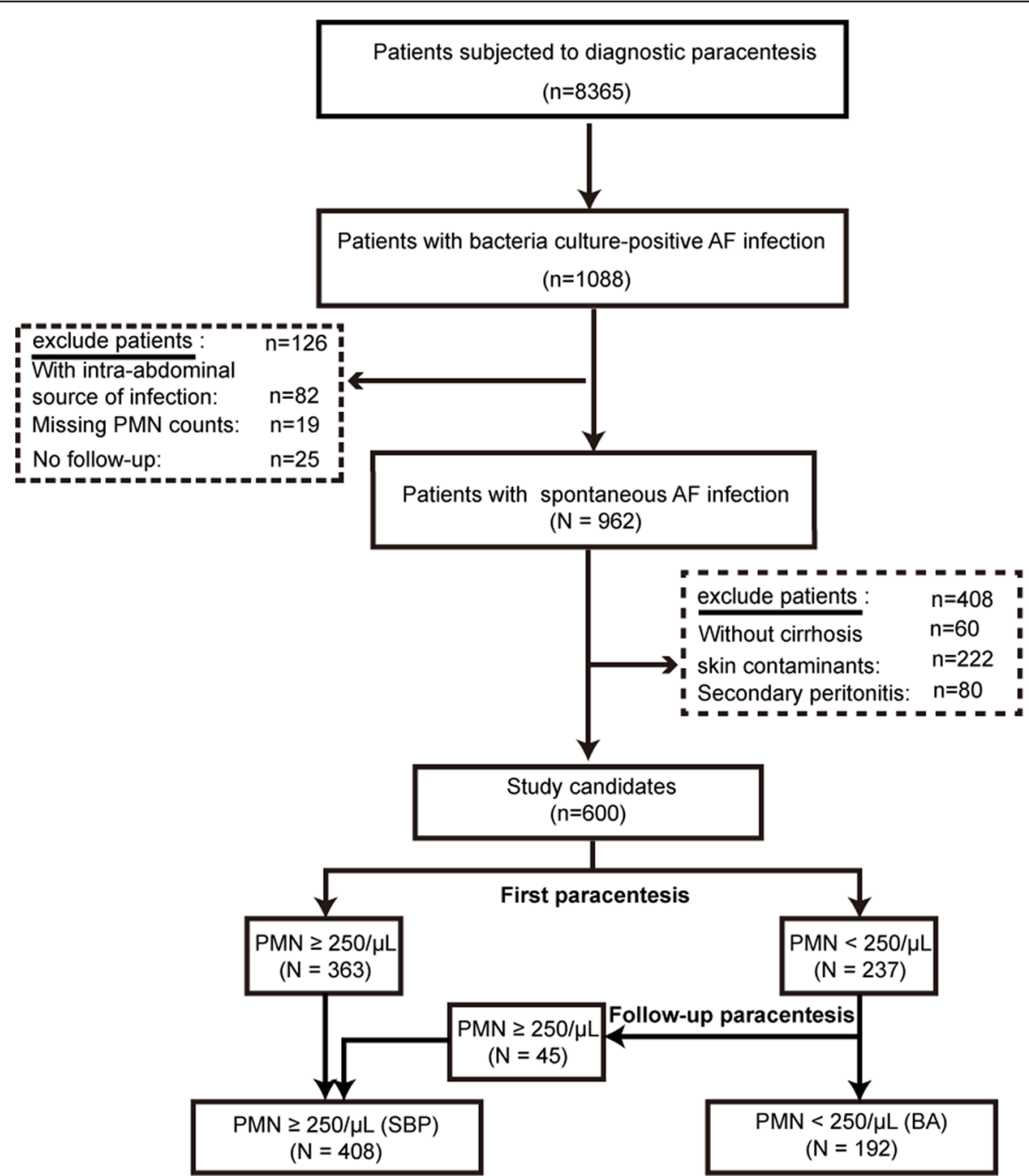

Fig. 1 Flowchart of patient enrollment in the study. Abbreviation: AF, ascitic fluid; SBP, spontaneous bacterial peritonitis; BA, bacterascites; PMN, polymorphonuclear leucocytes 
Table 1 Clinical and laboratory data of cirrhotic patients with BA and SBP

\begin{tabular}{|c|c|c|c|c|}
\hline & Total $(n=600)$ & $\mathrm{BA}(n=192)$ & $\operatorname{SBP}(n=408)$ & $p$ \\
\hline Sex (male) & $465(77.5 \%)$ & $144(75 \%)$ & $321(78.7 \%)$ & 0.314 \\
\hline Age $(y r)$ & $53.9 \pm 11.9$ & $55.7 \pm 12.1$ & $53.1 \pm 11.6$ & 0.011 \\
\hline Presentation of symptoms & $458(76.3 \%)$ & $118(61.5 \%)$ & $340(83.3 \%)$ & $<0.001$ \\
\hline Nosocomial infection & $287(47.8 \%)$ & $84(43.8 \%)$ & $203(49.8 \%)$ & 0.17 \\
\hline MELD score & $19.7 \pm 9.5$ & $16.3 \pm 7.9$ & $21.4 \pm 9.8$ & $<0.001$ \\
\hline Days in hospital & $13(7-19)$ & $13(7-18)$ & $13(7-19)$ & 0.732 \\
\hline Days between admission and onset of infection & $2(0-9)$ & $2(0-6)$ & $2(0-10)$ & 0.03 \\
\hline \multicolumn{5}{|l|}{ Causes of cirrhosis } \\
\hline Hepatitis B & $370(61.7 \%)$ & $105(54.7 \%)$ & $265(65 \%)$ & 0.016 \\
\hline Hepatitis C & $59(9.8 \%)$ & $24(12.5 \%)$ & $35(8.6 \%)$ & 0.132 \\
\hline Biliary & $22(3.7 \%)$ & $7(3.6 \%)$ & 15 (3.7\%) & 0.985 \\
\hline Alcoholic & $90(15 \%)$ & 37 (19.3\%) & 53 (13\%) & 0.044 \\
\hline Others & $59(9.8 \%)$ & $19(9.9 \%)$ & $40(9.8 \%)$ & 0.972 \\
\hline \multicolumn{5}{|l|}{ Serum features } \\
\hline $\mathrm{ALT}(\mathrm{U} / \mathrm{L})$ & $35.0(21.0-64.0)$ & $30.0(20.0-48.0)$ & $38.0(21.0-71.8)$ & 0.001 \\
\hline AST(U/L) & $60.0(37.0-105.8)$ & $53.0(33.0-86.0)$ & $65.5(39.0-111.8)$ & 0.004 \\
\hline Prealbumin(mg/L) & $47.2 \pm 25.8$ & $55.3 \pm 23.9$ & $43.4 \pm 25.8$ & $<0.001$ \\
\hline Prothrombin time(S) & $18.1(15.0-22.6)$ & $54.5(40.2-68.0)$ & $41.8(26.0-57.7)$ & $<0.001$ \\
\hline $\mathrm{BUN}(\mathrm{mmol} / \mathrm{L})$ & $8.0(5.1-13.2)$ & $6.4(4.8-9.9)$ & $8.9(5.4-14.4)$ & $<0.001$ \\
\hline 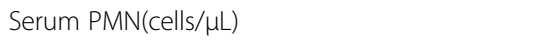 & $5.4(3.0-8.6)$ & $4.0(2.4-6.4)$ & $6.2(3.6-9.8)$ & $<0.001$ \\
\hline Serum WBC(cells/uL) & $6.9(4.3-10.5)$ & $5.4(3.4-8.3)$ & $7.7(5.1-11.6)$ & $<0.001$ \\
\hline Creatinine $(\mu \mathrm{mol} / \mathrm{L})$ & $97.5(78.0-138.8)$ & $90.0(70.2-111.8)$ & $105.0(82.0-157.0)$ & $<0.001$ \\
\hline Total protein(g/L) & $55.0(49.0-61.0)$ & $56.0(51.0-63.0)$ & $54.0(48.0-60.0)$ & 0.001 \\
\hline Total bilirubin ( $(\mu \mathrm{mol} / \mathrm{L})$ & $82.4(35.9-233.4)$ & $51.5(30.0-144.3)$ & $107.9(42.7-260.0)$ & $<0.001$ \\
\hline \multicolumn{5}{|l|}{ Ascitic features } \\
\hline Ascitic PMN(cells/ $\mu \mathrm{L})$ & 799.5 (53.1-5405.8) & $22.9(5.6-71.3)$ & 3099.9 (720.2-7873.0) & $<0.001$ \\
\hline Ascitic WBC(cells/ $\mu \mathrm{L})$ & $1241.0(253.3-6565.0)$ & $169.0(90.3-310.8)$ & 3850.5 (1119.3-9826.8) & $<0.001$ \\
\hline Hepatocellular carcinoma & $175(29.2 \%)$ & $49(25.5 \%)$ & $126(30.9 \%)$ & 0.178 \\
\hline Hepatic encephalopathy & $203(33.8 \%)$ & $58(30.2 \%)$ & $145(35.5 \%)$ & 0.198 \\
\hline Septic shock & $108(18 \%)$ & 19 (9.9\%) & $89(21.8 \%)$ & $<0.001$ \\
\hline Upper gastrointestinal bleeding & $114(19 \%)$ & $34(17.7 \%)$ & $80(19.6 \%)$ & 0.580 \\
\hline Diabetes mellitus & $101(16.8 \%)$ & 37 (19.3\%) & $64(15.7 \%)$ & 0.274 \\
\hline 30-day mortality & $131(21.8 \%)$ & $26(13.5 \%)$ & $105(25.7 \%)$ & 0.001 \\
\hline
\end{tabular}

Abbreviation: SBP spontaneous bacterial peritonitis, BA bacterascites, MELD Model for End-Stage Liver Disease, WBC white blood cell, PMN polymorphonuclear leukocytes, ALT alanine transarninase, $A S T$ aspartate aminotransferase, Bun blood urea nitrogen

$P$ :compared between BA and SBP. $P$-values $<0.05$ are indicated in bold

05 in the univariate analysis were candidates for multivariate analysis and non-significant factors were removed by a backward selection process. All tests were two-tailed and $p<0$. 05 were considered to be statistically significant. IBM SPSS Statistics 19.0 was used for statistical analyses.

\section{Results}

General characteristics and clinical presentation During the study period (January 1, 2012 to December $31,2015)$, a total of 8365 patients were subjected to diagnostic paracentesis. Ascitic fluid culture in blood culture bottles was positive in $13.0 \%(n=1088)$ of patients. The flowchart for patient enrollment was shown in Fig. 1, and only 600 ascitic fluid infection episodes (408 SBP and 192 BA) were identified in patients with cirrhosis and enrolled in this study (Fig. 1). Laboratory and clinical features at the time of diagnostic paracentesis were given in Table 1. Serum laboratory data (alanine transaminase/ALT, aspartate aminotransferase/ AST, prealbumin, BUN, creatinine, total protenin, total 
bilirubin, erythrocytes/WBC, PMN and prothrombin time) and ascitic features (WBC and PMN) of SBP were significantly higher than that of BA $(p<0.01)$. In additional, septic shock was more common in patients with SBP $(p<0.01)$. There were no significant differences in the percentage of nosocomial episodes between SBP and BA.

\section{Bacteriological characteristics and impact of drug resistance on mortality}

Among the 600 patients, 554 patients had monobacterial infection and the other 46 had polybacterial infection. Thus, a total of 656 pathogens were isolated from these patients and shown in Table 2. Gram-negative bacteria, accounting for $68.1 \%$ of pathogens in total, were more common than gram-positive bacteria. The major pathogens identified were Escherichia coli $(n=267,40$. $7 \%)$, Streptococcus spp. ( $n=110,16.8 \%)$, Klebsiella spp. ( $n=87,13.3 \%)$, Enterococcus spp. $(n=66,10.1 \%)$, Coagulase-positive staphylococci $(n=25,3.8 \%)$, Enterobacter spp. $(n=20,3.0 \%)$ and Acinetobacter spp. $(n=18,2.7 \%)$. In total, these 7 types of pathogens account for $90.4 \%$ ( $n$ $=593$ ) of the causative bacteria. The antimicrobial susceptibility of these bacteria was shown in Fig. 2a. Nearly half of Escherichia coli (49.4\%) were resistant to TGC, on the contrary, most of Klebsiella spp. isolates were sensitive to TGC. Vancomycin was a reliable agent for treating gram-positive pathogen infections because of the low resistant rates. Nine Acinetobacter baumannii strains were multidrug resistant. Multidrug resistant pathogens were associated with high 30-day mortality rate. Our data showed that patients infected with multidrug resistant Acinetobacter spp. had significantly higher 30-day mortality compared to patients infected with susceptible Acinetobacter spp. (100\% vs. $11.1 \%$, respectively, $p<0.001$, Fig. 2b). Survival curves shows that patients infected with TGC-resistant bacteria had a significantly lower survival probability than those with TGCsusceptible bacteria ( $p=0.001$, Fig. 2c). Also, there was a significantly lower survival probability for patients infected with carbapenem-resistant organisms than it was in carbapenem-susceptible cases $(p<0.001$, Fig. 2d). Levofloxacin-resistant organisms were not associated with greater mortality than levofloxacin-susceptible ones $(p=0.092$, Fig. 2e).

\section{Risk factors for BA progressing to SBP}

For 187 of 237 cases with ascitic fluid PMN counts $<250$ cells $/ \mu \mathrm{L}$ at the first paracentesis, a follow-up paracentesis was performed when culture results come back positive. In our hospital, if BA patient exhibited symptoms of peritonitis, the patient would be treated with empirical antibiotic immediately. The development of BA between the first and second paracentesis (usually $2-3$ days) was of

Table 2 Types of bacteria isolated from cultures of ascitic fluid in patients with cirrhosis

\begin{tabular}{|c|c|c|c|c|}
\hline \multirow[t]{2}{*}{ Isolates } & \multicolumn{4}{|c|}{ no.(\%) of isolates } \\
\hline & Total $(n=656)$ & $\mathrm{BA}(n=208)$ & $\operatorname{SBP}(n=448)$ & $P$ \\
\hline \multicolumn{5}{|l|}{ Gram-negative organisms } \\
\hline Total & $447(68.1 \%)$ & $116(55.8 \%)$ & $331(73.9 \%)$ & $<0.001$ \\
\hline Escherichia coli & $267(40.7 \%)$ & 71 (34.1\%) & $196(43.8 \%)$ & 0.020 \\
\hline Klebsiella spp. & 87 (13.3\%) & $20(9.6 \%)$ & 67 (15.0\%) & 0.061 \\
\hline Enterobacter spp. & $20(3.0 \%)$ & $5(2.4 \%)$ & $15(3.3 \%)$ & 0.513 \\
\hline Acinetobacter spp. & $18(2.7 \%)$ & $5(2.4 \%)$ & $13(2.9 \%)$ & 0.716 \\
\hline Aeromonas spp. & $9(1.4 \%)$ & $2(1.0 \%)$ & $7(1.6 \%)$ & 0.726 \\
\hline Citrobacter spp. & $8(1.2 \%)$ & $3(1.4 \%)$ & $5(1.1 \%)$ & 0.713 \\
\hline Serratia spp. & $7(1.1 \%)$ & $2(1.0 \%)$ & $5(1.1 \%)$ & 1.000 \\
\hline Burkholderia spp. & $5(0.8 \%)$ & $3(1.4 \%)$ & $2(0.4 \%)$ & 0.333 \\
\hline Pseudomonas spp. & $8(1.2 \%)$ & $1(0.5 \%)$ & 7 (1.6\%) & 0.446 \\
\hline Other & $18(4.0 \%)$ & $4(1.9 \%)$ & $14(3.1 \%)$ & - \\
\hline \multicolumn{5}{|l|}{ Gram-positive organisms } \\
\hline Total & 209 (31.9\%) & $92(44.2 \%)$ & $117(26.1 \%)$ & $<0.001$ \\
\hline Streptococcus spp. & $110(16.8 \%)$ & 47 (22.6\%) & $63(14.1 \%)$ & 0.006 \\
\hline Enterococcus spp. & $66(10.1 \%)$ & 29 (13.9\%) & $37(8.3 \%)$ & 0.024 \\
\hline Coagulase-positive staphylococci & $25(3.8 \%)$ & $11(5.3 \%)$ & $14(3.1 \%)$ & 0.178 \\
\hline Kocuria spp. & $3(0.5 \%)$ & $1(0.5 \%)$ & $2(0.4 \%)$ & 1.000 \\
\hline Other & $5(0.8 \%)$ & $4(1.9 \%)$ & $1(0.2 \%)$ & - \\
\hline
\end{tabular}

$P$ :compared between isolates collected from BA and SBP. $P$-values $<0.05$ are indicated in bold 
a

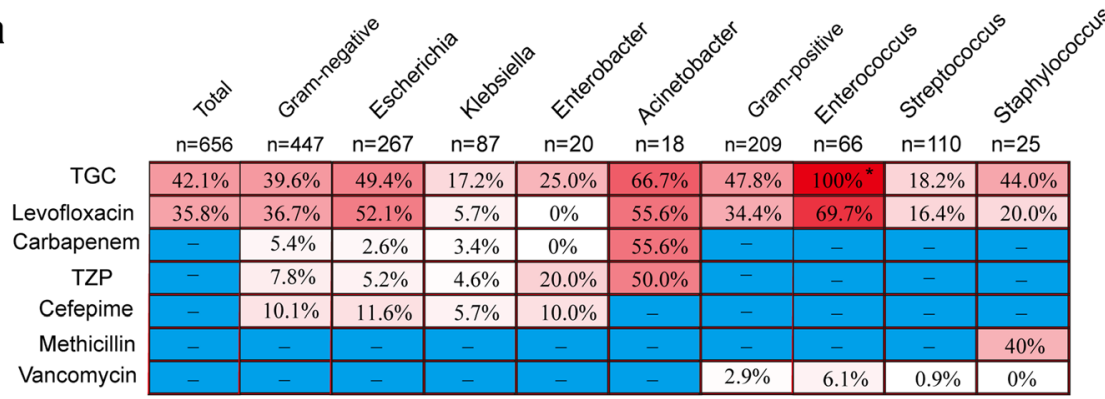

b
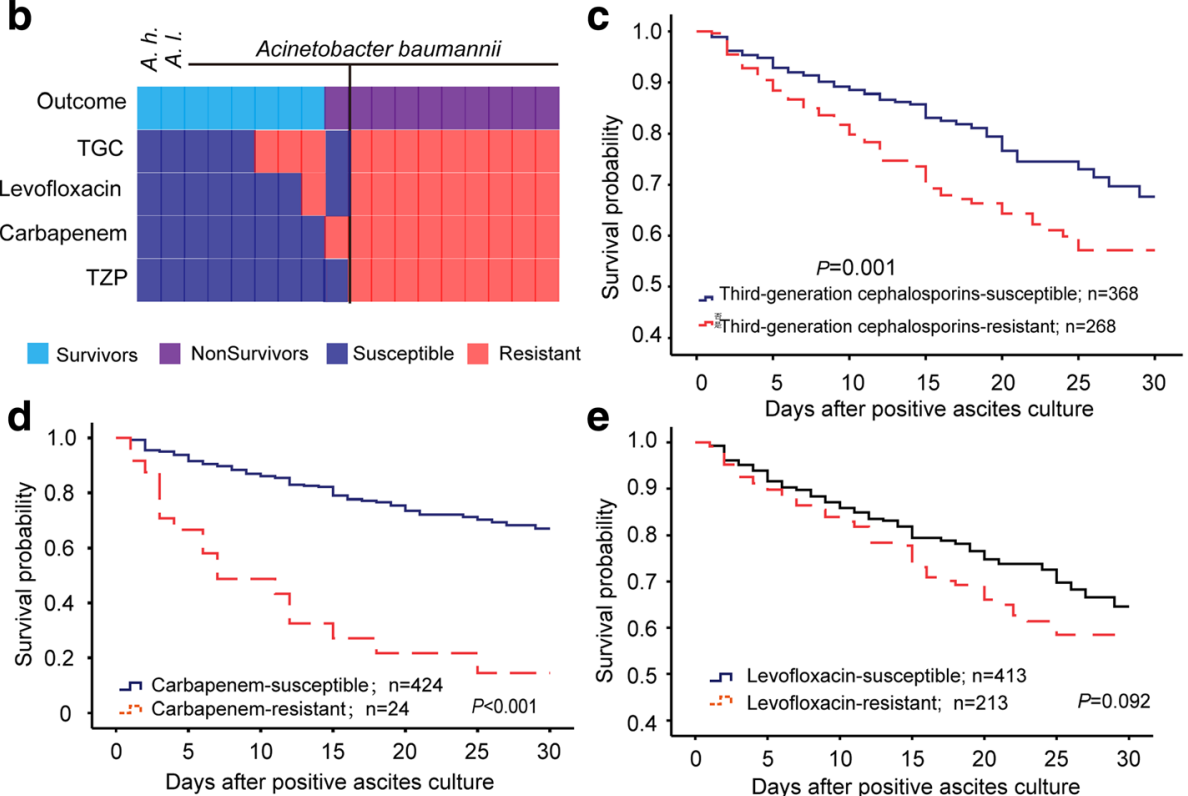

Fig. 2 Drug resistance of major bacteria and impact of antibiotic resistance on mortality. (a) Resistance to antibiotics among seven major isolates. * Enterococcus spp. is naturally resistant to third-generation cephalosporins (TGC). TZP, piperacillin/tazobactam. (b) Effect of multi-drug resistance on patient mortality with respect to Acinetobacter spp. A.h.: Acinetobacter haemolyticus; A.l: Acinetobacter Iwoffii. (c, d, e) 30-day survival curve for patients with positive ascites culture according to third-generation cephalosporin, carbapenem or levofloxacin resistance $(p=0.004,<0.001$ and $=0.092$, respectively)

concern. Thus, potential risk factors for BA progressing to SBP were identified (Table 3). Results showed that development of BA was associated with the severity degree of liver diseases (MELD score, $p<0.001)$, serum $\operatorname{PMN}(p=0$. $002)$, ascitic PMN $(p=0.002)$, presentation of fever $(p=0$. 036) and serious complications (hepatocellular carcinoma and septic shock, $p=0.035$ and 0.014 , respectively). In multivariate analysis, only the presentation of hepatocellular carcinoma $(\mathrm{OR}=3.047,95 \% \mathrm{CI}: 1.161-7.997, p=0.024)$ and higher ascitic PMN count $(\mathrm{OR}=1.007,95 \% \mathrm{CI}$ : 1 . $001-1.013, p=0.023)$ remained independent predictors for BA progressing to SBP.

Risk factors for 30-day mortality of patients with BA and SBP The 30-day mortality of patients with SBP was significantly higher than that of BA $(25.7 \%$ vs. $13.5 \%, p=0$. 001) (Table 1). We studied independent risk factors of 30-day mortality in BA and SBP respectively, and found that independent risk factors were different between them. Multivariate analysis, including the variables associated with mortality by univariate analysis, showed that the concentration of BUN was independent risk factor for 30-day mortality of BA patients (Table 4). For patients with SBP, the independent risk factors for 30-day mortality were age, MELD score, septic shock and hepatocellular carcinoma (Table 5).

\section{Impact of isolate type on clinical characteristics and mortality} To study the impact of isolate type on clinical characteristics and mortality, we limited the analysis to patients with monobacterial ascitic fluid infections. Clinical characteristics of patients infected with different types of bacteria were shown in (Additional file 1): Table S1. There were significant differences in clinical characteristics among the seven types of bacterial infection, for example the percentage of peritonitis symptoms, several clinical complications, type of peritonitis (SBP), nosocomial infection, serum and ascitic features, MELD score and days between admission 
Table 3 Risk factors for BA episodes progressing to SBP

\begin{tabular}{|c|c|c|c|c|c|c|}
\hline & \multirow{2}{*}{$\begin{array}{l}\text { Progress to SBP } \\
(n=45)\end{array}$} & \multirow{2}{*}{$\begin{array}{l}\text { No progress to } \\
\text { SBP }(n=142)\end{array}$} & \multicolumn{2}{|c|}{ Univariate analysis } & \multicolumn{2}{|c|}{ Multivariate analysis } \\
\hline & & & $\bar{P}$ & Odds ratio $(95 \% \mathrm{Cl})$ & $\bar{P}$ & Odds ratio $(95 \% \mathrm{Cl})$ \\
\hline Sex (male) & 37 (82.2\%) & $108(76.1 \%)$ & 0.390 & $0.687(0.292-1.616)$ & - & - \\
\hline Age (yr) & $52.4 \pm 9.2$ & $55.4 \pm 12.5$ & 0.144 & 0.979(0.951-1.007) & - & - \\
\hline Nosocomial infection & $23(51.1 \%)$ & $57(40.1 \%)$ & 0.197 & $1.559(0.795-3.059)$ & - & - \\
\hline MELD score & $23.0 \pm 10.7$ & $16.3 \pm 7.4$ & $<0.001$ & $1.089(1.046-1.133)$ & 0.503 & $1.036(0.934-1.149)$ \\
\hline $\begin{array}{l}\text { Days between admission } \\
\text { and onset of infection }\end{array}$ & $3(0-7.5)$ & $1(0-6)$ & 0.239 & $1.018(0.989-1.048)$ & - & - \\
\hline Fever & $30(66.7 \%)$ & 69 (48.6\%) & 0.036 & $2.116(1.049-4.268)$ & 0.053 & $2.533(0.986-6.505)$ \\
\hline Chills & $4(8.9 \%)$ & $11(7.7 \%)$ & 0.806 & $1.162(0.351-3.846)$ & - & - \\
\hline Abdominal pain & 15(33.3\%) & 34 (23.9\%) & 0.214 & $1.588(0.765-3.295)$ & - & - \\
\hline $\mathrm{ALT}(\mathrm{U} / \mathrm{L})$ & $42.0(24.0-106.0)$ & $30.0(20.0-49.0)$ & 0.011 & $1.005(1.001-1.009)$ & 0.326 & $1.004(0.996-1.011)$ \\
\hline AST(U/L) & $70.0(42.0-135.5)$ & $52.5(33.0-88.5)$ & 0.030 & $1.003(1.000-1.005)$ & 0.602 & $1.001(0.996-1.006)$ \\
\hline Prealbumin(mg/L) & $41.3 \pm 22.7$ & $56.1 \pm 24.8$ & 0.001 & $0.973(0.957-0.989)$ & 0.224 & $0.986(0.965-1.008)$ \\
\hline Prothrombin time(S) & $19.2(15.7-31.1)$ & $16.3(14.1-19.3)$ & $<0.001$ & $1.078(1.034-1.125)$ & 0.118 & $1.064(0.984-1.149)$ \\
\hline $\operatorname{Bun}(\mathrm{mmol} / \mathrm{L})$ & $8.6(5.5-13.9)$ & $6.6(4.8-11.5)$ & 0.074 & $1.039(0.996-1.083)$ & - & - \\
\hline 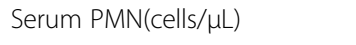 & $4.9(2.8-9.8)$ & $4.2(2.4-6.6)$ & 0.002 & $1.12(1.042-1.205)$ & 0.161 & $1.641(0.822-3.277)$ \\
\hline Serum WBC(cells/ $\mu \mathrm{L})$ & $6.1(4.0-11.8)$ & $5.4(3.6-8.5)$ & 0.006 & $1.096(1.027-1.17)$ & 0.223 & $0.671(0.353-1.275)$ \\
\hline Serum creatinine $(\mu \mathrm{mol} / \mathrm{L})$ & $105.0(82.0-159.0)$ & $88.5(70.8-113.5)$ & 0.15 & $1.003(0.999-1.006)$ & - & - \\
\hline Total protein(g/L) & $56.0(50.0-61.0)$ & $55.0(50.0-63.0)$ & 0.679 & $0.997(0.983-1.011)$ & - & - \\
\hline Total bilirubin ( $\mu \mathrm{mol} / \mathrm{L})$ & $98.5(43.9-311.4)$ & $51.9(32.4-140.2)$ & 0.018 & $1.002(1.000-1.005)$ & 0.36 & $0.998(0.994-1.002)$ \\
\hline Ascitic PMN(cells/ $\mu \mathrm{L})$ & $64.7(21.7-141.7)$ & $24.0(5.3-74.8)$ & 0.002 & $1.008(1.003-1.013)$ & 0.029 & $1.007(1.001-1.013)$ \\
\hline Ascitic WBC(cells/ $\mu \mathrm{L})$ & $257.0(114.5-370.0)$ & $161.0(91.8-302.8)$ & 0.529 & $1.000(0.999-1.002)$ & - & - \\
\hline hepatocellular carcinoma & $20(44.4 \%)$ & 39 (27.5\%) & 0.035 & $2.113(1.056-4.229)$ & 0.024 & $3.047(1.161-7.997)$ \\
\hline hepatic encephalopathy & $16(35.6 \%)$ & $43(30.3 \%)$ & 0.508 & $1.27(0.626-2.577)$ & - & - \\
\hline septic shock & $12(26.7 \%)$ & $16(11.3 \%)$ & 0.014 & $2.864(1.235-6.639)$ & 0.799 & $0.851(0.246-2.949)$ \\
\hline Gastrointestinal haemorrhage & $11(24.4 \%)$ & $29(20.4 \%)$ & 0.567 & $1.261(0.57-2.786)$ & - & - \\
\hline diabetes mellitus & $7(15.6 \%)$ & $28(19.7 \%)$ & 0.534 & $0.75(0.303-1.856)$ & - & - \\
\hline
\end{tabular}

$P$-values $<0.05$ and corresponding Odds ratio are indicated in bold

and onset of infection $(p<0.01)$. To investigate the impact of isolate type on the 30-day mortality, Cox proportional hazard model was used to control confounding variables, such as MELD score, defining isolate type as dummy variable (Table 6 and Additional file 1: Table S2). In univariate analysis, patients infected with Acinetobacter spp., Klebsiella spp. and Enterococcus spp. had higher hazard ratios of 30-day mortality compared to those infected with Escherichia coli. Multivariate analysis showed that only patients infected with Klebsiella spp. had higher hazard ratio of 30-day mortality compared to those with Escherichia coli (Table 6).

\section{Discussion}

In this study, we retrospectively investigated the clinical and bacteriological characteristics of 600 SBP and BA patients, and studied the outcomes of these patients. To our knowledge, this is the most comprehensive and largest dataset of patients with ascitic fluid infection from
China, and it permits statistical comparison and risk factor analysis for prognosis of SBP and BA.

Nearly half $(47.8 \%)$ of the ascitic fluid infection were nosocomial-acquired. It could be explained in part by that patients enrolled in this study underwent frequent hospitalization before they were admitted to our department and experienced long hospital stays. Previous studies also reported high nosocomial infection rates in those patients $[4,19]$. High rate of nosocomial-acquired SBP was not a common in China. Li et al. found that nearly two-thirds of SBP in cirrhotic patients was community-acquired in a hospital located in Zhejiang province of China [12].

In comparison with the data base of SBP, little data for $\mathrm{BA}$ is available. Previous researches indicated that many of patients with BA indeed were symptomatic and as a variant of spontaneous bacterial peritonitis [20, 21]. However, the difference between BA and SBP is uncertain and controversial because the lack of appropriate data sets and 
Table 4 Risk factors for 30-day mortality in patients with BA

\begin{tabular}{|c|c|c|c|c|c|c|}
\hline & \multirow{2}{*}{$\begin{array}{l}\text { Survivors } \\
(n=166)\end{array}$} & \multirow{2}{*}{$\begin{array}{l}\text { Nonsurvivors } \\
(n=26)\end{array}$} & \multicolumn{2}{|l|}{ Univariate analysis } & \multicolumn{2}{|l|}{ Multivariate analysis } \\
\hline & & & HR $(95 \% \mathrm{Cl})$ & $P$ & HR (95\% Cl) & $p$ \\
\hline Age (yr) & $55.3 \pm 12.2$ & $58.3 \pm 11.6$ & $1.022(0.991-1.055)$ & 0.162 & - & - \\
\hline Sex (male) & $125(75.3 \%)$ & 19 (73.1\%) & $1.152(0.484-2.742)$ & 0.750 & - & - \\
\hline Nosocomial infection & $68(41 \%)$ & $16(61.5 \%)$ & $2.21(1.000-4.884)$ & 0.050 & - & - \\
\hline MELD score & $14.7 \pm 6.8$ & $26.1 \pm 7.7$ & $1.153(1.102-1.207)$ & $<0.001$ & $1.054(0.988-1.125)$ & 0.108 \\
\hline $\begin{array}{l}\text { Days between admission } \\
\text { and onset of infection }\end{array}$ & $2(0-6)$ & $4.5(0-17.3)$ & $1.022(1.002-1.042)$ & 0.027 & 1.015 (0.986-1.045) & 0.301 \\
\hline Symptoms of peritonitis & $102(61.4 \%)$ & $16(61.5 \%)$ & $0.915(0.414-2.022)$ & 0.826 & - & - \\
\hline $\operatorname{ALT}(\mathrm{U} / \mathrm{L})$ & $28.0(19.0-46.0)$ & $45.5(28.0-93.3)$ & $1.003(1.000-1.006)$ & 0.036 & $1.001(0.992-1.009)$ & 0.861 \\
\hline AST(U/L) & $50.0(32.0-75.5)$ & $88.0(51.5-180.8)$ & $1.003(1.001-1.005)$ & 0.002 & $1.003(0.997-1.008)$ & 0.308 \\
\hline Prealbumin(mg/L) & $57.3 \pm 24.2$ & $42.6 \pm 17.8$ & $0.975(0.957-0.993)$ & 0.006 & $0.981(0.958-1.004)$ & 0.100 \\
\hline $\operatorname{Bun}(\mathrm{mmol} / \mathrm{L})$ & $5.9(4.7-9.1)$ & $11.5(7.7-15.5)$ & $1.099(1.055-1.143)$ & $<0.001$ & $1.1(1.033-1.173)$ & 0.003 \\
\hline Serum PMN (cells/ML) & $3.6(2.1-5.8)$ & $6.5(5.2-12.6)$ & $1.219(1.124-1.322)$ & $<0.001$ & $1.027(0.926-1.14)$ & 0.609 \\
\hline Total Protein(g/L) & $57.0(52.0-64.0)$ & $51.0(47.0-54.0)$ & $0.979(0.957-1.001)$ & 0.060 & - & - \\
\hline 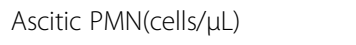 & $24.0(6.5-69.0)$ & $13.0(3.2-115.0)$ & $1.002(0.996-1.008)$ & 0.589 & - & - \\
\hline Hepatocellular carcinoma & $42(25.3 \%)$ & 7 (26.9\%) & $1.056(0.443-2.514)$ & 0.903 & - & - \\
\hline Hepatic encephalopathy & $39(23.5 \%)$ & $19(73.1 \%)$ & $6.442(2.704-15.346)$ & $<0.001$ & $2.382(0.849-6.679)$ & 0.099 \\
\hline Septic shock & $8(4.8 \%)$ & $11(42.3 \%)$ & $5.725(2.614-12.536)$ & $<0.001$ & $2.247(0.876-5.762)$ & 0.092 \\
\hline Gastrointestinal haemorrhage & $23(13.9 \%)$ & $11(42.3 \%)$ & $2.966(1.361-6.466)$ & 0.006 & $1.705(0.655-4.438)$ & 0.274 \\
\hline Diabetes mellitus & $34(20.5 \%)$ & $3(11.5 \%)$ & $0.576(0.1730-1.920)$ & 0.369 & - & - \\
\hline
\end{tabular}

$P$-values $<0.05$ and corresponding HR are indicated in bold

systematic analyses. In this retrospective study, we compared the clinical and bacteriological characteristics between SBP and BA. BA patients had lower 30-day mortality and less severe liver diseases than SBP patients, as evidenced by a lower serum ALT and AST and lower MELD scores, which is consistent with a previous report [21]. Symptoms of peritonitis, especially fever, and septic shock were less common in BA patients. In addition, gram-positive organisms, such as Streptococcus and Enterococcus, were more frequently found in BA than in SBP episodes. Our data also showed that hepatocellular carcinoma and higher ascitic PMN count were independent risk factors for BA episodes progressing to SBP. BA patients accompanied with hepatocellular carcinoma and higher ascitic PMN count thus should be optimal candidates for primary prophylaxis of SBP.

Consistent with previous studies, we also found that MELD score [22], the presentation of hepatocellular carcinoma [23] and presentation of septic shock [19] were independent risk factors for 30-day mortality at the time of SBP diagnosis. However, only the concentration of BUN were identified as independent predictive factor of 30-day mortality in patients with BA. To our knowledge, this is the first study to identify the independent risk factors of 30-day mortality in patients with BA. The independent risk factors of 30-day mortality were different between BA and SBP patients. The reason might be that SBP patients had higher MELD score and were thus sicker.

Prognosis of patients with ascitic fluid infection was influenced by bacterial antibiotic resistance. Our study suggested that resistant to TGC, which have been considered as first-line treatment of SBP [14, 24], were associated with lower survival probability. This result is consistent with previously studies [25-27]. Also, carbapenem-resistant gram-negative pathogen is a challenge for treating peritonitis. Our study showed that carbapenem-resistance is associated with significantly lower 30-day survival probability $(p<0.01)$. Thus, this can be a life-threatening factor for cirrhotic patients with ascitic fluid infection.

Gram-positive pathogens were increasingly recognized as important causative bacteria in patients with SBP and BA $[6,7,27,28]$. However, the impacts of those causative bacteria on the outcome of patients with ascitic fluid infection are less well understood. Polymicrobial infection would be a confounding factor in studying the impact of isolate type on characteristic and outcome of ascitic fluid infection. For instance, previous study have shown that Enterococci were of low virulence and were often found as a secondary invader in polymicrobial infections and the clinical relevance of enterococcal peritonitis is subject of debate [29]. Thus, we limited our 
Table 5 Risk factors for 30-day mortality in patients with SBP

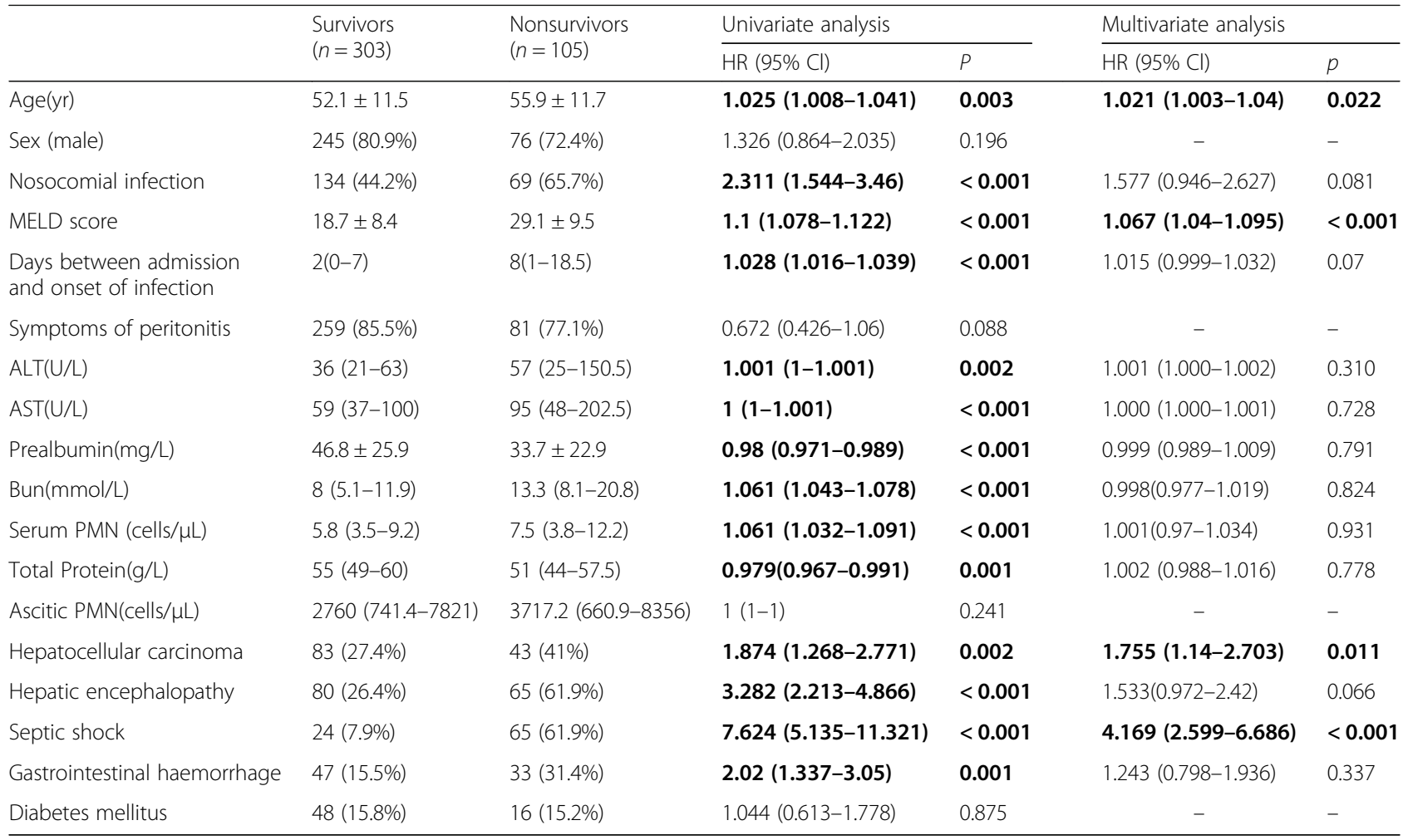

$P$-values $<0.05$ and corresponding HR are indicated in bold

analysis to patients with monobacterial peritonitis when investigating the impact of isolate type on clinical characteristics and mortality. Reuken et al. also limited their analysis to monobacterial peritonitis and found that enterococcal SBP patients had a poorer prognosis than nonenterococcal SBP [6]. In our study, we only observed higher hazard ratio of 30-day mortality in patients infected with Acinetobacter spp., Klebsiella spp. and Enterococcus spp. compared to those infected with Escherichia coli in univariate analysis. After adjusting for clinical parameters, however, only Klebsiella spp. infection $(\mathrm{HR}=1.888$, $95 \% \mathrm{Cl}, 1.092-3.265, p=0.024$ ) showed higher hazard ratio of 30-day mortality compared to that of Escherichia coli infection in multivariate analysis. Patients accompanied with Klebsiella spp. peritonitis seem to be associated with poorer prognosis even though those bacteria were less resistant against frequently used antimicrobial.

There were limitations in our study. First, our study was limited by being a single-center retrospective study. However, our hospital is a referral center for liver disease in the capital of China and many patients come from different regions of the country. Compared with a previous report [12], there were similar pathogen profiles and drug resistance in the two hospitals in China. The major pathogens in both hospitals were E. coli, K. pneumoniae, Enterococcus spp. and $S$. aureus. Furthermore, the

Table 6 Hazard ratios (HRs) for 30-day mortality of different types of bacteria against reference strains

\begin{tabular}{|c|c|c|c|c|}
\hline \multirow[t]{2}{*}{ Bacteria } & \multicolumn{2}{|l|}{ Univariate analysis } & \multicolumn{2}{|l|}{ Multivariate analysis } \\
\hline & HR $(95 \% \mathrm{Cl})$ & $P$ & $\mathrm{HR}(95 \% \mathrm{Cl})$ & $p$ \\
\hline Escherichia coli & Ref & & Ref & \\
\hline Coagulase-positive staphylococci & $0.298(0.041-2.161)$ & 0.231 & $0.399(0.054-2.929)$ & 0.367 \\
\hline Acinetobacter spp. & 3.881 (1.654-9.108) & 0.002 & $0.805(0.306-2.118)$ & 0.665 \\
\hline Enterobacter spp. & $2.385(0.944-6.025)$ & 0.066 & $1.537(0.572-4.131)$ & 0.394 \\
\hline Klebsiella spp. & $2.092(1.264-3.46)$ & 0.004 & $1.888(1.092-3.265)$ & 0.024 \\
\hline Enterococcus spp. & $2.842(1.644-4.911)$ & $<0.001$ & $0.964(0.513-1.813)$ & 0.911 \\
\hline Streptococcus spp. & $0.551(0.259-1.171)$ & 0.121 & $0.95(0.437-2.066)$ & 0.896 \\
\hline
\end{tabular}

Note: HRs were analyzed by using proportional hazards Cox regression model. In multivariate analysis, HR was adjusted for clinical parameters. Only the major monobacteria were included in analysis. Detailed information was shown in Table S2. P-values $<0.05$ and corresponding HR are indicated in bold 
resistant rate of gram-negative bacteria against TGC was both approximately $40 \%$. Thus, to a lesser extent, our data may be representative in SBP patients in China. Second, patients with culture-negative SBP (ascitic $\mathrm{PMN} \geq 250$ cells/ $\mu \mathrm{l}$ and a negative culture result) were not included in this study. Thus, our findings, such as independent risk factors of 30-day mortality in patients with SBP, could not be applied to those patients.

\section{Conclusions}

In conclusion, there were significant differences between BA and SBP regarding clinical and bacterial characteristics and 30-day mortality. Presentation of hepatocellular carcinoma and higher ascitic PMN count were independent risk factors for BA progressing to SBP. The concentration of BUN were identified as independent predictive factors of 30-day mortality in patients with BA. For patients with SBP, the independent risk factors for 30-day mortality were age, MELD score, septic shock and hepatocellular carcinoma. The Klebsiella spp. related peritonitis is of concern, because those infections are associated with poorer outcome. Strict infection control must be implemented to control the spread of third-generation cephalosporin or carbapenem-resistant pathogens.

\section{Additional file}

Additional file 1: Tables S1. Characteristics of patients with monobacterial ascitic fluid infection, by type of infecting bacteria. Table S2. Detailed information about hazard ratios (HRs) for 30-day mortality of different types of bacteria against reference strains. (DOC $90 \mathrm{~kb}$ )

\section{Abbreviations}

ALT: Alanine transaminase; AST: Aspartate aminotransferase;"

BA: Bacterascites;" BUN: Blood urea nitrogen; MELD: End-Stage Liver Disease“ PMN: Polymorphonuclear;; SBP: Spontaneous bacterial peritonitis;; TGC: Thirdgeneration cephalosporins; WBC: White blood cell;

\section{Acknowledgments}

We thank LetPub (www.letpub.com) for its linguistic assistance during the preparation of this manuscript.

\section{Authors' contribution}

HW, FQ and CMB conceived, initiated and designed the study and coordinated drafting the manuscript. NZN, TL and JLZ collected data, carried out data analysis and wrote the manuscript. WG, WH and SYZ were responsible for the data collection, reviewing medical charts and assisted in data analysis. JH, XL and ZL assisted in data analysis and in performing statistical analyses. JLF checked the issues of clinical data, reviewed and commented the manuscript. All authors read and approved the final manuscript.

\section{Funding}

This work was supported by National Key Basic Research Program (973) of China (2015CB554202), National Natural Science Foundation of China (81401643), the State Key Research Development Program of China (2016YFC1200301), the science and technology plan program of Beijing, China (Z151100003915151), the State Key Laboratory of Pathogen and Biosecurity Program (SKLPBS1530) and the Beijing Nova Program (Z181100006218111).
Availability of data and materials

All data generated or analysed during this study are included in this published article [and its Additional file 1].

\section{Ethics approval and consent to participate}

The study was reviewed and approved by the Beijing 302 Hospital Research Ethics Committee. The Beijing 302 Hospital Research Ethics Committee waived the need for written informed consent from the participants due to the deidentified secondary data analyzed in this study.

\section{Competing interests}

The authors declare that they have no competing interests.

\section{Publisher's Note}

Springer Nature remains neutral with regard to jurisdictional claims in published maps and institutional affiliations.

\section{Author details}

${ }^{1}$ The State Key Laboratory of Pathogen and Biosecurity, Beijing Institute of Microbiology and Epidemiology, No.20 Dongda Street, Fengtai District, Beijing 100071, China. ${ }^{2}$ Clinical Diagnostic Center, Beijing 302 Hospital, No. 100 Western 4th Middle Ring Road, Beijing 100039, China. ${ }^{3}$ Research Center for Biological Therapy, Institute of Translational Hepatology, Beijing 302 Hospital, Beijing 100039, China.

Received: 8 August 2017 Accepted: 17 April 2018

Published online: 04 June 2018

\section{References}

1. Arvaniti V, D'Amico G, Fede G, Manousou P, Tsochatzis E, Pleguezuelo M, Burroughs AK: Infections in patients with cirrhosis increase mortality fourfold and should be used in determining prognosis. Gastroenterology 2010, 139(4):1246-1256, 1256.e1241-1245.

2. European Association for the Study of the L. EASL clinical practice guidelines on the management of ascites, spontaneous bacterial peritonitis, and hepatorenal syndrome in cirrhosis. J Hepatol. 2010;53(3):397-417.

3. Ricart E, Soriano G, Novella MT, Ortiz J, Sabat M, Kolle L, Sola-Vera J, Minana J, Dedeu JM, Gomez C, et al. Amoxicillin-clavulanic acid versus cefotaxime in the therapy of bacterial infections in cirrhotic patients. J Hepatol. 2000;32(4):596-602.

4. Campillo B, Richardet JP, Kheo T, Dupeyron C. Nosocomial spontaneous bacterial peritonitis and bacteremia in cirrhotic patients: impact of isolate type on prognosis and characteristics of infection. Clin Infect Dis. 2002;35(1):1-10.

5. Angeloni S, Leboffe C, Parente A, Venditti M, Giordano A, Merli M, Riggio O. Efficacy of current guidelines for the treatment of spontaneous bacterial peritonitis in the clinical practice. World J Gastroenterol. 2008;14(17):2757-62.

6. Reuken PA, Pletz MW, Baier M, Pfister W, Stallmach A, Bruns T. Emergence of spontaneous bacterial peritonitis due to enterococci - risk factors and outcome in a 12-year retrospective study. Aliment Pharmacol Ther. 2012; 35(10):1199-208

7. Piroth L, Pechinot A, Di Martino V, Hansmann Y, Putot A, Patry I, Hadou T, Jaulhac B, Chirouze C, Rabaud C, et al. Evolving epidemiology and antimicrobial resistance in spontaneous bacterial peritonitis: a two-year observational study. BMC Infect Dis. 2014;14:287.

8. Fernandez J, Acevedo J, Castro M, Garcia O, de Lope CR, Roca D, Pavesi M, Sola E, Moreira $L$, Silva $A$, et al. Prevalence and risk factors of infections by multiresistant bacteria in cirrhosis: a prospective study. Hepatology. 2012;55(5):1551-61.

9. Alexopoulou A, Papadopoulos N, Eliopoulos DG, Alexaki A, Tsiriga A, Toutouza M, Pectasides D. Increasing frequency of gram-positive cocci and gram-negative multidrug-resistant bacteria in spontaneous bacterial peritonitis. Liver Int. 2013;33(7):975-81.

10. Fiore M, Maraolo AE, Gentile I, Borgia G, Leone S, Sansone P, Passavanti MB, Aurilio C, Pace MC. Nosocomial spontaneous bacterial peritonitis antibiotic treatment in the era of multi-drug resistance pathogens: A systematic review. World J Gastroenterol. 2017;23(25):4654-60.

11. Wang FS, Fan JG, Zhang Z, Gao B, Wang HY. The global burden of liver disease: the major impact of China. Hepatology. 2014;60(6):2099-108.

12. Li YT, Yu CB, Huang JR, Qin ZJ, Li LJ. Pathogen profile and drug resistance analysis of spontaneous peritonitis in cirrhotic patients. World J Gastroenterol. 2015;21(36):10409-17. 
13. Gou YZ, Liu B, Pan L, Yu HT, Wang JP, Wang DC. Pathogens of spontaneous bacterial peritonitis change in northern China. Saudi medical journal. 2010; 31(10):1152-6.

14. Runyon BA. Management of adult patients with ascites due to cirrhosis: an update. Hepatology. 2009;49(6):2087-107.

15. Rimola A, Garcia-Tsao G, Navasa M, Piddock LJ, Planas R, Bernard B, Inadomi $J M$. Diagnosis, treatment and prophylaxis of spontaneous bacterial peritonitis: a consensus document. International Ascites Club. J Hepatol. 2000;32(1):142-53.

16. Kamath PS, Wiesner RH, Malinchoc M, Kremers W, Therneau TM, Kosberg CL, D'Amico G, Dickson ER, Kim WR. A model to predict survival in patients with end-stage liver disease. Hepatology. 2001;33(2):464-70

17. Merli M, Lucidi C, Giannelli V, Giusto M, Riggio O, Falcone M, Ridola L, Attill AF, Venditti M. Cirrhotic patients are at risk for health care-associated bacterial infections. Clin Gastroenterol Hepatol. 2010:8(11):979-85.

18. Wayne PA. Methods for dilution antimicrobial susceptibility tests for bacteria that grow aerobically; approved standard-ninth edition M07-A9. CLSI. 2012

19. Cheong HS, Kang Cl, Lee JA, Moon SY, Joung MK, Chung DR, Koh KC, Lee NY, Song JH, Peck KR. Clinical significance and outcome of nosocomial acquisition of spontaneous bacterial peritonitis in patients with liver cirrhosis. Clin Infect Dis. 2009;48(9):1230-6

20. Chu CM, Chang KY, Liaw YF. Prevalence and prognostic significance of bacterascites in cirrhosis with ascites. Dig Dis Sci. 1995;40(3):561-5.

21. Runyon BA. Monomicrobial nonneutrocytic bacterascites: a variant of spontaneous bacterial peritonitis. Hepatology. 1990;12(4 Pt 1):710-5.

22. Tandon P, Kumar D, Seo YS, Chang HJ, Chaulk J, Carbonneau M, Qamar H, Keough A, Mansoor N, Ma M. The 22/11 risk prediction model: a validated model for predicting 30-day mortality in patients with cirrhosis and spontaneous bacterial peritonitis. Am J Gastroenterol. 2013;108(9):1473-9.

23. Tsung PC, Ryu SH, Cha IH, Cho HW, Kim JN, Kim YS, Moon JS. Predictive factors that influence the survival rates in liver cirrhosis patients with spontaneous bacterial peritonitis. Clin Mol Hepatol. 2013;19(2):131-9.

24. EASL clinical practice guidelines on the management of ascites, spontaneous bacterial peritonitis, and hepatorenal syndrome in cirrhosis. Journal of hepatology 2010, 53(3):397-417.

25. Hung TH, Tsai CC, Hsieh YH, Tsai CC, Tseng CW, Tsai JJ. Effect of renal impairment on mortality of patients with cirrhosis and spontaneous bacterial peritonitis. Clin Gastroenterol Hepatol. 2012;10(6):677-81.

26. Ariza X, Castellote J, Lora-Tamayo J, Girbau A, Salord S, Rota R, Ariza J, Xio $X$. Risk factors for resistance to ceftriaxone and its impact on mortality in community, healthcare and nosocomial spontaneous bacterial peritonitis. J Hepatol. 2012;56(4):825-32

27. Umgelter A, Reindl W, Miedaner M, Schmid RM, Huber W. Failure of current antibiotic first-line regimens and mortality in hospitalized patients with spontaneous bacterial peritonitis. Infection. 2009;37(1):2-8.

28. Bert F, Noussair L, Lambert-Zechovsky N, Valla D. Viridans group streptococci: an underestimated cause of spontaneous bacterial peritonitis in cirrhotic patients with ascites. Eur J Gastroenterol Hepatol. 2005;17(9):929-33.

29. Harbarth S, Uckay I. Are there patients with peritonitis who require empiric therapy for enterococcus? Eur J Clin Microbiol Infect Dis. 2004;23(2):73-7.

\section{Ready to submit your research? Choose BMC and benefit from:}

- fast, convenient online submission

- thorough peer review by experienced researchers in your field

- rapid publication on acceptance

- support for research data, including large and complex data types

- gold Open Access which fosters wider collaboration and increased citations

- maximum visibility for your research: over $100 \mathrm{M}$ website views per year

At BMC, research is always in progress.

Learn more biomedcentral.com/submissions 